to general atheroma and cardiovascular disease. Although the treatment is kept relatively elementary, the work is of high fundamental scientific merit.

The very rapidly expanding field of lipids and lipoproteins has been compressed within 5 brief chapters and this has been achieved by selecting essential information and omitting details which are available in larger reference works.

The nomenclature, chemical composition and classification of lipoproteins are described. The tissues in which the lipoproteins are synthesized, metabolized and catabolized are discussed.

The clinical implication of hypercholesterolaemia and hypertriglyceridaemia and the major risk factors which are important in the aetiology of atherosclerosis are well presented.

A small chapter is devoted to the benefits of risk factor intervention. Since it is well recognized that the chances of atherosclerosis are meagre, early intervention by dietary management and avoidance of cigarette smoking has been suggested.

The measurement of lipids and lipoproteins and the interpretation of the results are briefly documented.

The authors suggest that the merits of intervention may be debatable in survivors of a myocardial infarct but any of their relatives with significant hyperlipidaemia who are still free of cardiovascular disease may be important subjects to benefit by such intervention.

The final chapter gives a practical guidance to the management of hyperlipidaemia by dietary management and by drug therapy.

\section{Medical Neurology.}

By J. Gilroy and J. S. Meyer. 3rd edn. Pp. ix +787 , illustrated. Macmillan Publishing, New York; Collier Macmillan, Toronto; Ballière Tindall, London, 1980. $£ 21.00$.

This is a textbook of general neurology from the United States of America, for students. The United Kingdom has always had a good supply of neurological textbooks but this one could be at home on either side of the Atlantic.

The book is too simple for the trained neurologist who needs authoritative sources but the neurologist in training or someone training in general (internal) medicine would find it instructive.

It would have been helpful if at the beginning of each chapter there had been a list of the main topics covered. The first chapter concerns examination of the nervous system and gives a good general introduction to clinical neurology. The actions of the muscles moving the eye are poorly described in the early part of the chapter (pages 21 and 22) so that the signs noted with paralysis, described later (page 32) cannot be explained logically. There is a good separate chapter on paediatric neurology which with developmental neurology has become a separate speciality. With improved postnatal care patients with congenital brain disease or birth trauma are more likely to survive, and careful developmental assessment is needed to pick up the milder problems.

For a book published in 1979 one would have expected a fuller assessment of evoked responses in the diagnosis of multiple sclerosis. The book gives 8 diagnostic procedures used including computed brain tomography but says "visual evoked responses ... have a complementary role in the diagnosis of multiple sclerosis'. Evoked potentials give the clinician a better idea of nerve conduction within the central nervous system than any other test and as nerve conduction is the function most disturbed in multiple sclerosis, the evoked potentials can only become increasingly important. They deserve more space than neuropsychological testing as a diagnostic tool.

It is good to see the value of computed brain tomography appreciated but in clinical neurology it is not always as help- ฏ ful in the differential diagnosis of the various degenerative and similar diseases as is implied by the considerable space

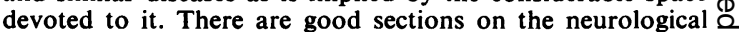
complications of heavy metal and industrial poisoning and on $c$. infections of the central nervous system.

The chapter on cerebrovascular disease starts with a full account of the arterial system followed by a good description of the common syndromes which are well illustrated with arteriograms. The section on cerebral tumours is more than adequate for a book on medical neurology.

Optic atrophy is considered in the section on peripheral and cranial nerves but as the optic'nerve' is really a part of the brain and not a nerve, the various causes of optic atrophy are probably best discussed in the chapters on diseases in the $\vec{\nabla}$ central nervous system. The rest of the chapter on peripheral nerve diseases and the one on muscle disease give a clear account of their subjects.

On the whole, this is a satisfactory book which gains coherence by being the work of only two authors.

\section{Mental Handicap Nursing and Care}

By Victoria Shennan. Pp. 208, illustrated. Human

Horizons Series, Souvenir Press, London, 1980. £5.95 (paperback £3.95).

The book is written primarily for trainee nurses and therapists with the recommendations of the Jay Report in mind. It sets out in simple terms the role of the nurse in the long-term care of the mentally handicapped. It stresses the importance of sympathetic understanding of the rights and needs of the mentally handicapped and their families, combined with change in attitude and flexibility in their care.

It provides information on Basic Health Care, Specialised Hospital Nursing, Therapy Techniques and Community Pre vision. It covers the management of problems most likely to occur at specific stages in development, infancy, during the school years at puberty and into adulthood. The section the development of sexuality, sexual behaviour and marria is excellent.

The early part of the book on the Definition and Classification of Mental Handicap is confusing, particularly as the grades of retardation mild and moderate in the W.H.O. classification are not synonymous with 'mild and moderately retarded people' as used in the educational categories referred to later in the text. It is a pity to find the terms mongol and mongolism used in a book of this quality together with some statements which cannot be substantiated, e.g. the cause of tiptoe gait.

When assessing development, a 40-week-old baby would not be expected to build one brick on another or feed himself with a spoon, more significant findings are the development of a pincer grasp, pointing with the index finger, and searching behaviour.

This reviewer would like to see more emphasis given to the need to refer handicapped children for ophthalmological examination even though this examination may occasionally prove difficult; similarly audiological assessment is important, particularly in Down's syndrome.

Overall, the book is a valuable introduction to the subject and includes a useful Bibliography and List of Resources.

The Normal Child. Some Problems of the Early Years and their Treatment.

By R. S. Illingworth. 7th edn. Pp. ix +353 , illustrated. Churchill Livingstone, Edinburgh, London and New York, 1979. £9.00.

The Normal Child has become a classic work which is known and respected by many. It first appeared 27 years ago and now enters its 7 th edition, having been translated into Spanish, Greek and Japanese. The subject matter is extensive (1) . \title{
员
} , , 
and includes sections on infant feeding, growth and development, and the problems of normal and disturbed behaviour. Throughout, emphasis is given to those common problems and conditions which have not always been recognized as variations of normality. The author does not avoid contentious issues and with rare exceptions gives practical and authoritative advice on management. There is a degree of imbalance between some of the sections, perhaps reflecting the author's special interests. Thus, 4 pages on circumcision replete with quotations from Kenyatta to the Koran is a little excessive and in contrast to the limited section on tonsillectomy. In general, the style is charaterized by the brevity and pungency we have come to expect from the author and is certainly never dull.

Perhaps the greatest compliment to this book is the degree to which its contents have been accepted and incorporated into so many other paediatric texts. It is commended to doctors, medical students and nurses who work with children, both in hospital and in the community as an essential and readable companion to the standard works.

\section{Practical Gastrointestinal Endoscopy.}

By P. B. Cotton and C. B. Williams. Pp. $x+185$, illustrated. Blackwell Scientific Publications, Oxford, London, 1980. £13.50.

Fibre-optic endoscopy results from the brilliant discovery by Professor Harold Hopkins of the University of Reading. It is a sad reflection on the present state of this country that our inventive genius is no longer combined with manufacturing capability, since all the endoscopic instruments now used in our hospitals are manufactured abroad - principally in Japan and Germany. However, leaving these nationalistic considerations aside, there is no doubt that fibre-optic endoscopy has revolutionized not only our diagnostic, but also our therapeutic practice. There is now no hollow organ immune from the prying eye of brilliantly designed instruments, and ingenious biopsy forceps, cutting loops, dilators, etc., enable many procedures to be carried out by 'closed' techniques.

As more and more gastrointestinal endoscopic units are becoming established, staffed by interested physicians, surgeons or radiologists, there is a need for practical guides, and so this volume by two leading authorities on gastrointestinal endoscopy is more than welcome. Practical details are given on basic instrumentation, care of instruments, design of the endoscopy unit, patient preparation and documentation. There are good descriptions of special techniques such as palliative intubation of malignant strictures of the oesophagus, endoscopic retrograde cannulation of the biliary and pancreatic ducts, endoscopic removal of gall stones from the common bile duct and colonic polypectomy Endoscopy during acute upper gastrointestinal bleeding rightly receives special consideration.

The text is clearly produced, the diagrams are profuse and helpful and there is a useful bibliography. This is a book that gastroenterologists with an interest in endoscopy - and this means nearly all of them - will find a useful addition to their library.

\section{Survey Methods in Community Medicine.}

By J. H. Abramson. 2nd edn. Pp. 229. Churchill Livingstone, Edinburgh, London and New York, 1979. £5.00.

This book deals with the design and conduct of surveys in medicine from the first idea to the writing of the report. Each chapter follows logically on to the next until the whole subject has been covered in a thoroughly practical way.

It begins with the types and stages in an investigation, the objectives and how to formulate them with a special section on evaluative studies. This is followed by chapters on the study population, the control groups, sampling methods, the defining of variables and of diseases, scales of measurements and composite measurements. Details are given on the methods of collecting data, their reliability and validity, the use of interviews and self-administered questionnaires, how to construct questionnaires in general and the use of documentary sources. The need to plan the analysis early is discussed before the chapters on coding, recording, collection and processing of data. Finally, there are sections on the interpretation of the findings, making sense of associations, generalizing from the results and the writing of the report. Despite the title, the methods described are equally applicable to hospital or community medicine.

Professor Abramson describes his book as an ABC to the design and conduct of studies. It is indeed this but it is also more than this, for the copious notes and references make it useful for those who wish to study the subject in greater detail, while his sense of humour and easy style help to lighten a difficult subject.

The advent of the computer and simpler methods of processing and analysing data has led to a rapid increase in the number of surveys being carried out in medicine. Some produce conflicting results which are often due to methodological differences and readers unused to the pitfalls may uncritically accept the lastest findings or dismiss them all. This is a book therefore whose value is not confined to those who undertake surveys but can assist writers and readers alike to a more informed and discerning approach to the many studies which are being carried out in medicine.

\section{Tredgold's Mental Retardation.}

Edited by Michael Craft with 18 contributors. 12th edn. Pp. xiv +384 , illustrated. Baillière Tindall, London, 1979. f16.00.

This book first appeared in 1908 and now enters its 12th edition. Such longevity does testimony to its role as a standard work and to the success with which continuing editions have been adapted during seven decades of the evolution of the subject. The authorship now includes 19 contributors from 3 continents who have sought to bring together the many related disciplines involved in the recognition and management of mental retardation. Thus, in addition to an extensive and well illustrated clinical section, other subject areas embrace the psychiatry and education of the retarded child and adult, the legal aspects encountered in England, Scotland and the United States of America, and the administrative and operational problems involved in classification, team work, planning and organization of services. The final section contains chapters on the specialized but important problems of parent counselling, the relationship with both autism and epilepsy, and the management of the violent and dangerous patient. If any criticism had to be made it might be argued that the scope of the subject matter is too broad to allow a sufficiently full treatment in all of the chapters. Thus, the clinical descriptions of the primary genetic and acquired disorders tend to be synoptic compared with the fuller treatment afforded to them in standard texts. The 300 words allocated to lead intoxication do little to reflect the present day controversy surrounding the subject and this section contains 2 potentially dangerous errors in which the upper acceptable limit for blood lead concentration in children is given as $3.6 \mathrm{mg} / \mathrm{dl}$ (instead of $36 \mu \mathrm{g} / \mathrm{dl}$ ) or $0.18 \mathrm{mmol} / \mathrm{l}$ (instead of 1.8 $\mu \mathrm{mol} / \mathrm{l})$. It is unlikely that this book will appeal to those concerned with early recognition and diagnosis except in so far as it gives a readable perspective to the long-term problems which will ultimately be encountered. Nevertheless, it is commended for all those who work in the long-term care and management of the mentally retarded as a useful reference source which has been successful in highlighting the new and expanding aspects of what has now become a multidisciplinary field. 